\title{
Comparative Trade Policy
}

\author{
Magnus Wiberg*
}

May 20, 2010

\begin{abstract}
Current research has found ambiguous results with respect to the effects of the type of electoral regime on trade policy. The present paper proposes a solution to this indeterminacy. It is shown that the equilibrium level of trade protection can be relatively higher, as well as lower, under a majoritarian electoral rule compared to proportional representation. The equilibrium outcome is shown to depend on the number of voters in swing districts who own a factor specific to the exporting industry in relation to those who possess claims to the specific input employed by the import-competing sector. It is further argued that political rents are lower (higher) under majoritarian elections if there are more factor owners in the swing districts with stakes in the exporting (import-competing) industry.

Keywords: Endogenous Tariff Formation; Trade Policy; Electoral Rules JEL Classification: D72; F13
\end{abstract}

\footnotetext{
*This paper was written when the author was visiting the Department of Economics, Harvard University, Littauer Center, 1805 Cambridge Street, Cambridge, MA 02138. Current affiliation: Swedish Government Offices. SE-103 33 Stockholm, Sweden. E-mail: magnus.wiberg@finance.ministry.se. Phone: 0046737271224.
} 


\section{Introduction and Related Literature}

There is a large consensus in the literature that trade policy is determined by the interaction of politicians, interest groups, and voters. Given this view, why are some countries more protectionist than others? Political science links policy choices to fundamental constitutional features such as, for example, the electoral rule employed. Can this institutional arrangement provide an explanation for the cross-country variation in trade politics? If so, the constitutional design is of economic importance for newly emerging democracies, but also for more consolidated democratic regimes seeking to change their election scheme. ${ }^{1}$ Unfortunately, evidence from recent research is conflicting and inconclusive regarding which type of electoral system produces the most protectionist policy. The primary aim of the current paper is to solve this ambiguity.

While the specific question of how constitutional rules influence trade policy has been neglected until recently, much of the work on comparative political economy studies aspects of fiscal policy. Persson and Tabellini (1999), for example, relate the size and composition of government spending to the political system. In a Downsian model of electoral competition and forwardlooking voting it is shown that majoritarian, as opposed to proportional, elections increase competition between parties by focusing it into some key marginal (swing) districts. This leads to less public goods, less rents for politicians, more redistribution and larger government.

The analysis has its trade policy counterpart in a theoretical and empirical study by Roelfsema (2004), who argues that countries with a majoritarian electoral system are more inclined to have a high level of trade protection. The reason is a higher competition intensity for swing districts compared to countries with proportional representation. Following this view, Persson (2005) makes the case that since proportional democracies seek consensus

\footnotetext{
${ }^{1}$ Recently, Italy replaced its system of proportional representation, where legislators were elected according to the proportions of the popular national vote received by their parties, with one that includes ingredients of plurality rule, where legislators are elected in each district according to who receives the highest number of votes. A number of other countries have implemented related reforms. For instance, after the referendum of 1993, New Zealand altered its system of plurality rule in single-member districts to a system mixing elements of proportional representation. In France, the Socialist Party switched from the two-round majority system to PR for the 1986 elections. Japan moved to a system that mixes elements of proportional and plurality representation from its special form of plurality rule. The UK has debated similar proposals.
} 
among broader coalitions of voters, they should have relatively less protectionist trade policies. Moreover, if proportional representation leads to the election of legislators who maximize aggregate welfare, because their election is not tied to particular geographic or economic interests, then the model of Grossman and Helpman (2005) predicts higher average rates of protection in countries with majoritarian elections. Willman (2008) comes to the same conclusion using a citizen-candidate model with majoritarian voting and strategic delegation. In this setting, the median voter of a typical electoral district ignores the negative externality of protection imposed on other constituencies by electing delegates to a national legislature who represent the interests of those who own more than the district average amount of sector-specific capital. The extent of strategic delegation, and the ensuing level of protection, is shown to be increasing in the number of districts, which is relatively lower under the proportional system.

Hatfield and Hauk (2004), on the other hand, obtain the opposite result, that proportional systems have higher average tariffs than majoritarian institutions. In their model this is due to the proportional legislature weighting each domestic industry by its share of workers in the tariff formation process, while under the majoritarian electoral rule, the winning coalition of sectors does not consider the consequences of not raising the tariffs on the industries not included in the coalition, thus leading to lower overall tariffs.

The present paper shows that both these policy outcomes are possible by incorporating an export industry, producing for foreign markets using a sector-specific factor, into a model of endogenous trade policy with probabilistic voting (Lindbeck and Weibull, 1987). ${ }^{2}$ A given fraction of the population owns this specific input, and consequently has a direct stake in the exporting industry. The remaining individuals are the owners of a specific factor used by an import-competing sector, and therefore have a common interest in this sector. Within this framework, it is argued that trade policy is more (less) restrictive (i.e., characterized by more import protection and higher export taxation or less export subsidies) under proportional electoral regimes, as compared to majoritarian institutions, if marginal districts are populated by relatively more (less) factor owners with stakes in the exporting industry. This result is explained by a stiffer electoral competition in the majoritarian system, where politicians focus relatively more on the type of

\footnotetext{
${ }^{2}$ Roelfsema (2004), Grossman and Helpman (2005), and Hatfield and Hauk (2004) also apply the probabilistic voting model outlined in Lindbeck and Weibull (1987).
} 
factor owners who represent the largest fraction of the voting population in the swing districts. The election outcome is more sensitive to policy, and therefore the more dominant, or decisive, type obtains a trade policy closer to its bliss point as compared to proportional representation. This in turn implies a relatively higher (lower) level of protection under the proportional electoral rule. ${ }^{3}$

The paper also has implications for electoral competition and rent seeking in a small open economy. Persson and Tabellini (1999) argue that since the electoral competition is stiffer under the majoritarian electoral rule, parties become relatively more disciplined and forego some prospective political rents. This seems to suggest that less consolidated democracies, associated with pervasive rent seeking, optimally should apply the proportional system to maximize rent-seeking income. However, Norris (2008) finds that countries using proportional representation consistently rate as the most democratic, where rent seeking is low, while majoritarian systems proved consistently less democratic. Within the current framework it is shown that majoritarian elections make politicians forego rents at a higher (lower) rate compared to the proportional system if and only if there are relatively more factor owners in the swing districts with stakes in the exporting (import-competing) sector. The reason is that higher rents translate into a more protectionist trade policy, which creates a negative externality on the voters who own claims to the specific input used in the exporting industry. The majoritarian regime promotes a more intense political competition that to a relatively larger extent internalizes the policy preferences of the type of factor owners who belong to the dominant fraction of the voting population in the districts with the least ideological bias. When there are relatively more factor owners with stakes in the exporting (import-competing) sector in these districts, it becomes politically optimal to apply a relatively lower (higher) level of rent seeking under majoritarian elections.

The remainder of the paper is organized as follows. Section 2 expands

\footnotetext{
${ }^{3}$ It is assumed that trade policy can be set with some degree of national discretion. However, the main results still hold if politics are constrained by trading arrangements, given the view that the domestic political environment restricts the actions that governments take in international economic negotiations. Also it should be noted that under the World Trade Organization, the applied tariffs (that is, the level of protection below the official rates legally committed to) change frequently depending on the supply, demand, and political situation in each specific country (United States Department of Agriculture, 2004).
} 
on the economic framework, while Section 3 introduces the political economy dimension, solves for the trade policy and equilibrium rents in a proportional and majoritarian electoral regime, and provides a comparative analysis. Concluding comments are made in the closing section.

\section{Economic Framework}

The economic setting is a modification of the model of Grossman and Helpman (1994).

\subsection{Consumption and Production}

Consider a small open economy consisting of three firms: an exporting firm $(X)$, an import-competing firm $(M)$, and a firm $(Z)$ producing a numeraire good. ${ }^{4}$ The numeraire product uses labor alone with constant returns to scale. By assumption, aggregate labor supply is sufficiently large to ensure a positive output of this good. Units are chosen such that the wage paid to labor is one. Both nonnumeraire industries produce, with constant returns to scale technology, a good using labor and a sector-specific input supplied inelastically. The exporting industry sends its entire output to some foreign markets, while the import-competing sector produces solely for the domestic market in competition with foreign suppliers. ${ }^{5}$

The economy is populated by individuals with identical preferences but different factor endowments. Following Chang et al. (2009) in their application of the model of Grossman and Helpman (1994), each agent maximizes a utility function of the form:

$$
U=x_{Z}+u(x) .
$$

$x_{Z}$ represents consumption of the numeraire good, where the corresponding world and domestic price are equal to one. $x=y_{C}+m_{C}$ stands for consumption of the homogenous products $y$ and $m$ supplied to the domestic market,

\footnotetext{
${ }^{4}$ The model can be generalized to allow for many firms in each sector.

${ }^{5}$ This assumption is made for simplicity. All results generalize if the exporting (importcompeting) sector sells a majority of its production to the foreign markets (domestic market).
} 
where $y$ is the total amount of the commodity manufactured by the importcompeting sector, and $m$ is aggregate imports. ${ }^{6}$ Denote by $p_{w}$ the exogenous and common world price of these goods, while $p=p_{w}+t$ represents the domestic price, where $t$ stands for the specific tariff, or import subsidy, levied on imports. The subutility function $u(x)$ possesses the standard properties of differentiability and strict concavity, and leads to a demand function of the form: $x=d(p)=\left(u^{\prime}(x)\right)^{-1}$. The consumer devotes the remainder of his total spending of $E$ to the numeraire good, thereby attaining the utility level:

$$
v(p, E)=E+s(p),
$$

where $s(p) \equiv u(d(p))-p d(p)$ is the consumer surplus per capita derived from imported goods and domestically produced import-competing commodities.

Let $\pi(p)$ denote the aggregate domestic rent accruing to the specific factor used in producing the import-competing good. Similarly, let $\pi^{*}\left(p^{*}\right)$ stand for the domestic aggregate reward to the specific factor used in producing the exporting good, where $p^{*}=p_{w}^{*}+e$ is the domestic price of exports. $p_{w}^{*}$ and $e$ represent, respectively, the corresponding world price and specific export subsidy, or export tax, imposed on domestic exporters.

If the world price, $p_{w}\left(p_{w}^{*}\right)$, is normalized to unity, the domestic price of an import-competing (exporting) good is: $p=1+t\left(p^{*}=1+e\right)$. Hence, a price $p\left(p^{*}\right)$ in excess of one implies an import tariff (export subsidy), $t>0(e>0)$, on foreign (domestic) exports. A price below unity corresponds to import subsidies (export taxes), $t<0(e<0)$, on foreign (domestic) export products. ${ }^{7}$ Using Hotelling's lemma gives the supply curve for the domestic import-competing (exporting) commodity: $\pi^{\prime}(t)=y(t) \geq 0$ $\left(\pi^{* \prime}(e)=y^{*}(e) \geq 0\right)$.

A typical individual owns one unit of labor and derives income from wages, either by working in the exporting, import-competing or the numeraire industry; from government transfers in the form of tariff revenues, net of the cost of export subsidies, redistributed uniformly to the public; and from the ownership of some domestic sector-specific factor. By assumption,

\footnotetext{
${ }^{6}$ The analysis can be extended to allow for product differentiation.

${ }^{7}$ The foreign tariff or import subsidy levied on domestic exports, and the export subsidy or export tax imposed on foreign exporters by foreign governments have been suppressed in the expressions for $p$ and $p^{*}$ for notational convenience and with no loss of generality. The aim of this paper is to solve for the equilibrium trade policy of one country under different electoral rules.
} 
claims to these specific inputs are indivisible and nontradable, and the representative individual owns at most one type. Thus, those who own some of the specific input employed in a particular industry will have a direct stake in the tax or subsidy applicable to trade in the good produced by the sector in question that goes beyond their general interest as consumers.

This concludes the description of the economic model. The next section introduces the policy formation process under proportional and majoritarian elections.

\section{Political Framework}

The political setting considered is a modification of the model by Persson and Tabellini (1999), which in turn is based on the probabilistic voting approach adapted by Lindbeck and Weibull (1987).

\subsection{The Basic Setting}

Assume that elections involve the set of candidates, or parties, $\{A, B\}$, which is fixed and finite; candidates strive to maximize their vote share or, alternatively, their probability of winning; candidates simultaneously choose the policy vector $\boldsymbol{\tau}=(t, e)$; having observed the candidates' platforms, voters decide which candidate to vote for, and voting is costless. In addition, the candidates' commitments to their announced trade policy platforms, ahead of the elections, are assumed to be binding.

Besides $\boldsymbol{\tau}$, the parties may differ in some other dimension unrelated to policy. This dimension is referred to as ideology, but it could also involve other attributes such as the personal characteristics of the party leadership. The ideological dimension is a permanent feature in that it cannot credibly be modified as part of the electoral platform. Furthermore, by assumption, voters differ in their evaluation of these features.

The population consists of citizens belonging to different electoral districts indexed, in the same way as industries, by $j=M, X, Z$ (a citizen of district $j$ is interchangeably referred to as a member of voter group $j$ ), where the population size of each district is defined by a continuum of voters with unit mass. Consider then the following two simplifying assumptions: the three electoral districts coincide with the three sectors in the economy; ${ }^{8}$

\footnotetext{
${ }^{8}$ This approach is similar to the one taken by Willmann (2008). It can be shown that
} 
constituents in district $X$ and $M$ own the factor specific to that particular industry, while a fraction $\alpha_{X}\left(1-\alpha_{X}=\alpha_{M}\right)$ of the voting population in district $Z$ owns the specific input used by the exporting (import-competing) sector. ${ }^{9}$ Accordingly, to highlight the geographical concentration of industries, the three different sectors of the current specific factors model are associated with electoral districts, populated by individuals with stakes in either the exporting or the import-competing industry.

At the time of the elections, voters base their voting decision both on the trade policy announcements and on the two candidates' ideologies. Specifically, voter $i$ in group $j$ prefers candidate $A$ if:

$$
W_{j}\left(\boldsymbol{\tau}^{A}\right)>W_{j}\left(\boldsymbol{\tau}^{B}\right)+\sigma_{i j}+\delta .
$$

$\sigma_{i j}$ is an individual-specific parameter that can take on negative as well as positive values. It measures the individual ideological bias of voter $i$ towards candidate $B$. A positive value of $\sigma_{i j}$ implies that voter $i$ has a bias in favor of party $B$, whereas voters with $\sigma_{i j}=0$ are ideologically neutral, i.e., they care only about trade policy. Assume that this parameter has group-specific uniform distributions on: $\left[-\frac{1}{2 \phi_{j \neq Z}}+\bar{\sigma}_{j \neq Z}, \frac{1}{2 \phi_{j \neq Z}}+\bar{\sigma}_{j \neq Z}\right]$ in voter group $j \neq$ $Z$, where $\bar{\sigma}_{j \neq Z}$ denotes the average ideology, and $\phi_{j \neq Z}$ is the density of the distributions, which captures the voters' responsiveness to policy. ${ }^{10}$

Since income inequality in the electorate is derived from differences in input ownership, those in group $X(M)$ have the same marginal probabilistic response to income, and welfare $W_{X}\left(W_{M}\right)$, as the agents belonging to the fraction $\alpha_{X}\left(\alpha_{M}\right)$ of voter group $Z$. That is, voters with the same factor endowment are equally responsive to policy from the perspective of both

all results generalize if districts and sectors do not completely overlap, provided that there are relatively more exporting (import-competing) firms located in district $X(M)$. (See, for example, Persson and Tabellini [2002] for an application on public good provision.) Moreover, geographic concentration is widely used as a proxy for political concentration (i.e., the spread of industry across political districts). Busch and Reinhardt (1999) provide an overview of the literature on this topic.

${ }^{9}$ This assumption is made for simplicity. All results still hold if constituents with a common interest in the exporting (import-competing) industry own some, but not a majority, of the endowment of the specific factor used in the import-competing (exporting) sector.

${ }^{10}$ As Persson and Tabellini (2002) point out, the properties of the equilibrium do not change in a qualitative substantial way for more general distributions of voters' ideological preferences, namely if the group distributions of the parameter $\sigma_{i j}$ are not uniform, but unimodal. 
parties. ${ }^{11}$ Hence, the distribution of individual ideology in group $Z, \sigma_{i Z}$, differs across the two types of factor owners in the following way: $\sigma_{i Z_{X}} \sim$ $\left[-\frac{1}{2 \phi_{X}}+\bar{\sigma}_{X}, \frac{1}{2 \phi_{X}}+\bar{\sigma}_{X}\right]$ and $\sigma_{i Z_{M}} \sim\left[-\frac{1}{2 \phi_{M}}+\bar{\sigma}_{M}, \frac{1}{2 \phi_{M}}+\bar{\sigma}_{M}\right] \cdot{ }^{12}$ Thus two parameters, $\bar{\sigma}_{j \neq Z}$ and $\phi_{j \neq Z}$, fully characterize the distributions. Specifically, factor owners differ in their average ideology, captured by the means, $\bar{\sigma}_{j \neq Z}$, and in their ideological homogeneity, a higher density, $\phi_{j \neq Z}$, being associated with a narrower distribution of $\sigma_{i j}$. Hence, $\phi_{j \neq Z}$ measures the height of the distributions, and how many voters are gained among factor owners with a stake in sector $j \neq Z$ per marginal increase in their economic welfare.

The parameter $\delta$, which captures the average (relative) popularity of candidate $B$ in the population as a whole, can be positive or negative, and is uniformly distributed on: $\left[-\frac{1}{2 \psi}, \frac{1}{2 \psi}\right]$. As seen below, $\delta$ generates the required uncertainty about the election outcome.

The timing of the political process is as follows. (1) The two candidates, simultaneously and noncooperatively, announce their trade policy: $\tau^{A}$ and $\tau^{B}$. At this stage, they know the voters' policy preferences. They also know the distributions of $\sigma_{i j}$ and $\delta$, but not yet their realized values. (2) The actual value of $\delta$ is realized and all uncertainty is resolved. (3) Elections are held. (4) The elected candidate implements the announced policy platform.

To formally study the candidates' decisions at Stage 2, the swing voter in group $j$ is identified; that is, a voter whose ideological bias, given the candidates' platforms, makes him indifferent between the two parties:

$$
\sigma_{j}=W_{j}\left(\boldsymbol{\tau}^{A}\right)-W_{j}\left(\boldsymbol{\tau}^{B}\right)-\delta,
$$

where all voters $i$ in group $j$ with $\sigma_{i j} \leq \sigma_{j}$ prefer party $A$. Hence, given the distributional assumptions, the actual vote share of candidate $A$ in group $j$ is:

$$
\varpi_{A, j}=\phi_{j}\left(\sigma_{j}-\bar{\sigma}_{j}+\frac{1}{2 \phi_{j}}\right) .
$$

\footnotetext{
${ }^{11}$ Econometric studies (using micro-level survey data) on individual trade policy preferences by Balistreri (1997), Beaulieu (2002), Scheve and Slaughter (2001) find that the type of factor ownership has been the dominant determinant of support for, or opposition to, trade barriers for both Canada and the U.S.

${ }^{12}$ This implies that $\sigma_{Z}$ and $\phi_{Z}$ can be expressed as the weighted mean of the corresponding ideological parameters of the two types of factor owners belonging to the numeraire district: $\sigma_{Z}=\sum_{j \neq Z} \alpha_{j} \sigma_{Z_{j}}$ and $\phi_{Z}=\sum_{j \neq Z} \alpha_{j} \phi_{j}$.
} 
Since $\sigma_{j}$ depends on the realized value of $\delta$, the vote share is also a random variable. From both candidates' perspective, the electoral outcome is thus a random event, related to the realization of $\delta$.

\subsection{Proportional Elections}

Consider trade policy under an electoral rule where it is equally important to win votes in all voter groups. By assumption, there is perfect proportional representation in the sense that the parties obtain a seat share in perfect proportion to their vote share in the entire population. Furthermore, the party which obtains more than fifty percent of the seats earns the right to set policy according to its political platform. ${ }^{13}$ Under this electoral rule the probability of candidate $A$ winning is given by:

$$
P_{A}=P\left(\frac{1}{3} \sum_{j} \varpi_{A, j} \geq \frac{1}{2}\right) .
$$

Without loss of generality, assume that $\sum_{j} \phi_{j} \bar{\sigma}_{j}=0$. Given (3.2), the probability of winning then becomes:

$$
P_{A}=\frac{1}{2}+\frac{\psi}{3 \phi}\left(\sum_{j} \phi_{j}\left(W_{j}\left(\boldsymbol{\tau}^{A}\right)-W_{j}\left(\boldsymbol{\tau}^{B}\right)\right)\right),
$$

where $\phi \equiv \frac{\sum_{j} \phi_{j}}{3}$ is the average density across groups, and $\phi_{Z} W_{Z} \equiv \sum_{j \neq Z} \alpha_{j} \phi_{j} W_{j}{ }^{14}$

The welfare associated with candidate $A$ of a representative owner of the specific factor used in industry $M$ and $X$ is:

\footnotetext{
${ }^{13}$ For countries with proportional systems, more than two parties are usually observed. It should be noted, though, that the theory of probabilistic voting can be extended to multiparty elections - that is, elections involving three or more parties. For example, Dorussen et al. (1997) show that when the random component of voter decision making is sufficiently large, the so-called "minimum-sum point," which minimizes the average distance between voters and the parties' positions, represents a convergent equilibrium. This generalizes the results for two-party competition to the multiparty setting. The current assumption of two political candidates is accordingly made for simplicity. However, very commonly, parties sort themselves out before the elections into two party coalitions, each of which is vying for a majority of the electorate. See for example Petterson-Lidbom (2008) who characterizes the Swedish multiparty proportional system as bipartisan.

${ }^{14} \phi_{Z} W_{Z}$ can thus be interpreted as the weighted social welfare function of group $Z$. The definition implies that both parties internalize the number of voters in district $Z$ with a common interest in sector $j \neq Z\left(\alpha_{j \neq Z}\right)$ as well as their responsiveness to policy $\left(\phi_{j \neq Z}\right)$.
} 


$$
W_{M}\left(\boldsymbol{\tau}^{A}\right)=l+\bar{\pi}\left(t^{A}\right)+r\left(\boldsymbol{\tau}^{A}\right)+s\left(t^{A}\right)
$$

and

$$
W_{X}\left(\boldsymbol{\tau}^{A}\right)=l+\bar{\pi}^{*}\left(e^{A}\right)+r\left(\boldsymbol{\tau}^{A}\right)+s\left(t^{A}\right),
$$

where $l=1$ stands for the labor supply (and also labor income from working in the exporting, import-competing or the numeraire sector) of an owner of the specific input employed by industry $j \neq Z . \bar{\pi}\left(t^{A}\right) \equiv \frac{\pi\left(t^{A}\right)}{1+\alpha_{M}}$ and $\bar{\pi}^{*}\left(e^{A}\right) \equiv$ $\frac{\pi^{*}\left(e^{A}\right)}{1+\alpha_{X}}$ denote the per capita rent accruing to the specific factor used in producing import-competing and exporting goods, respectively. $r\left(\boldsymbol{\tau}^{A}\right) \equiv$ $\frac{t^{A} m\left(t^{A}\right)-e^{A} y^{*}\left(e^{A}\right)}{3}$ is the per capita revenue from trade taxes imposed on aggregate imports, $m\left(t^{A}\right)$, net of subsidies distributed to domestic exporters. $W_{M}\left(\boldsymbol{\tau}^{B}\right)$ and $W_{X}\left(\boldsymbol{\tau}^{B}\right)$ are defined analogously.

A unique equilibrium exists in which both $A$ and $B$ choose the same $\boldsymbol{\tau}$. Formally, they share the same first-order conditions, and do not themselves have preferences over policy. It follows from (3.5) that the equilibrium vector is a weighted mean of the two types of factor owners' individually optimal policy choices. The weights correspond to the total number of voters with stakes in industry $j \neq Z$, i.e., $1+\alpha_{j \neq Z}$, but also to the densities of swing voters among the factor owners, $\phi_{j \neq Z}$, since the densities summarize how responsive the different factor owners are to trade policy; that is, how they reward policy with votes at the elections.

To characterize the equilibrium $t$ under a proportional electoral system, (3.5) is maximized with regard to $t^{A}$, taking $t^{B}$ as given, using (3.6) and $(3.7):{ }^{15}$

$$
t^{P R O}=-\frac{y\left(t^{P R O}\right)\left(1+\alpha_{X}\right)\left(\phi_{M}-\phi_{X}\right)}{m^{\prime}\left(t^{P R O}\right)\left(\phi_{M}\left(1+\alpha_{M}\right)+\phi_{X}\left(1+\alpha_{X}\right)\right)},
$$

where $m^{\prime}\left(t^{P R O}\right)<0$. Solving for the optimal $e$, using the same procedure, $15 \frac{\partial r\left(\boldsymbol{\tau}^{A}\right)}{\partial t^{A}}=\frac{m\left(t^{A}\right)+t^{A} m^{\prime}\left(t^{A}\right)}{3}, \frac{\partial s\left(t^{A}\right)}{\partial t^{A}}=-d\left(t^{A}\right)=-y_{C}\left(t^{A}\right)-m_{C}\left(t^{A}\right)=$
$-\frac{y\left(t^{A}\right)+m\left(t^{A}\right)}{3}$. Hence, $\frac{\partial W_{M}\left(\boldsymbol{\tau}^{A}\right)}{\partial t^{A}}=\frac{y\left(t^{A}\right)}{1+\alpha_{M}}+\frac{m\left(t^{A}\right)+t^{A} m^{\prime}\left(t^{A}\right)}{3}-\frac{y\left(t^{A}\right)+m\left(t^{A}\right)}{3}$, and $\frac{\partial W_{X}\left(\boldsymbol{\tau}^{A}\right)}{\partial t^{A}}=$
$\frac{m\left(t^{A}\right)+t^{A} m^{\prime}\left(t^{A}\right)}{3}-\frac{y\left(t^{A}\right)+m\left(t^{A}\right)}{3}$. Substituting these expressions into the first-order condition
for $(3.5)$, solving for the optimum $t$, and rearranging terms yield (3.8). 
to obtain: ${ }^{16}$

$$
e^{P R O}=\frac{y^{*}\left(e^{P R O}\right)\left(1+\alpha_{M}\right)\left(\phi_{X}-\phi_{M}\right)}{y^{* \prime}\left(e^{P R O}\right)\left(\phi_{M}\left(1+\alpha_{M}\right)+\phi_{X}\left(1+\alpha_{X}\right)\right)},
$$

where $y^{* \prime}\left(e^{P R O}\right)>0$.

It is optimal for the two parties to equate the marginal gain of votes to the marginal loss of votes. The equilibrium therefore involves a supportive trade policy towards the factor owners with the highest density, because they are the most responsive voters. Hence, if $\phi_{M}>\phi_{X}$, foreign and domestic exports are taxed, that is, $t^{P R O} \geq 0$ and $e^{P R O} \leq 0$. Intuitively, a tax on imports increases the domestic price of the import-competing good, while taxing exports decreases the domestic price of the exporting good. This in turn increases the reward to the specific factor used in the import-competing sector, and decreases the return to the specific input used in producing the exporting good. The welfare cost of a higher price of imports, net of tax revenues, is borne uniformly by both types of factor owners. Trade taxation thus entail a negative externality on the individuals who own claims to the specific input employed in the exporting sector, who are taxed as both factor owners and consumers, and do not share in the benefits of a more restrictive trade policy.

On the other hand, if $\phi_{M}<\phi_{X}$, foreign and domestic exports are subsidized, i.e., $t^{P R O} \leq 0$ and $e^{P R O} \geq 0$, which decreases the price of imports and increases the domestic price of exports. This decreases the return to the specific factor used in the import-competing industry, and increases the reward to the specific input used by the exporting sector, while the benefit of a lower price on imports, net of the subsidy cost, accrues to both types of factor owners. Hence, such a policy combination creates a negative externality on the individuals with a stake in the import-competing industry, who as consumers share in the overall benefits to the economy of liberalized trade, but in their capacity as factor owners incur welfare losses.

Thus, the politically optimal trade policy is an import and export tax (subsidy) when the number of swing voters within the group of owners of the specific factor used by industry $M$ is strictly greater (less) than among those

\footnotetext{
$16 \frac{\partial r\left(\boldsymbol{\tau}^{A}\right)}{\partial e^{A}}=-\frac{y^{*}\left(e^{A}\right)+e^{A} y^{* \prime}\left(e^{A}\right)}{3} . \quad \frac{\partial W_{M}\left(\boldsymbol{\tau}^{A}\right)}{\partial e^{A}}=-\frac{y^{*}\left(e^{A}\right)+e^{A} y^{* \prime}\left(e^{A}\right)}{3}$, and $\frac{\partial W_{X}\left(\boldsymbol{\tau}^{A}\right)}{\partial e^{A}}=$ $\frac{y^{*}\left(e^{A}\right)}{1+\alpha_{X}}-\frac{y^{*}\left(e^{A}\right)+e^{A} y^{* \prime}\left(e^{A}\right)}{3}$. Using these expressions in the first-order condition for $(3.5)$, solving for the optimum $e$, and rearranging terms give (3.9).
} 
with a common interest in sector $X$. (It is more convenient to refer to the number of voters instead of the density, even though the distributions of the ideological parameters are assumed to be continuous.)

Also note that free trade prevails if $\phi_{M}=\phi_{X}$, which implies that $t^{P R O}=$ $e^{P R O}=0$. In this case, the two types of factor owners neutralize one another, so that the demand for trade taxation is matched in equilibrium by preferences for subsidies.

\subsection{Majoritarian Elections}

What if elections are instead conducted under plurality rule in one-seat electoral districts? First, assume that the candidate that obtains fifty percent or more of the vote in a district gains the seat in the legislature. Then add the following winning rule: earning the right to set policy requires winning at least two seats out of three. As Persson and Tabellini (1999) point out, this setting can be interpreted as a parliamentary election in which two competing parties field candidates running on the same platform in all three districts. The party winning in a majority of the districts has a majority in the assembly and can thus implement its preannounced trade policy.

Following Persson and Tabellini (1999), let $\bar{\sigma}_{X}<\bar{\sigma}_{M}$, thus $\bar{\sigma}_{X}<\bar{\sigma}_{Z}<\bar{\sigma}_{M}$ since $\sigma_{Z}=\sum_{j \neq Z} \alpha_{j} \sigma_{Z_{j}}$, where $\bar{\sigma}_{Z}=0$ is assumed without loss of generality. Suppose that this ideological bias towards party $A$ in group $X$ and towards party $B$ in group $M$ are large enough so that the group-specific means, $\bar{\sigma}_{X}$ and $\bar{\sigma}_{M}$, are sufficiently distant from zero. Then there exists an equilibrium with policy convergence, where the entire political competition takes place in the marginal district, $Z .{ }^{17}$ Party $A$ wins district $X$ with a large enough probability, and loses district $M$ with a large enough probability so that neither party finds it optimal to seek voters outside the marginal district, since only two districts are required for winning the election. In this setting, the relevant expression for the probability of candidate $A$ winning is just the probability that $A$ wins district $Z$. Using the definition of $\phi_{Z} W_{Z}$, this can be written as:

$$
P_{A}=P\left(\varpi_{A, Z} \geq \frac{1}{2}\right)=\frac{1}{2}+\frac{\psi}{\phi_{Z}}\left(\sum_{j \neq Z} \alpha_{j} \phi_{j}\left(W_{j}\left(\boldsymbol{\tau}^{A}\right)-W_{j}\left(\boldsymbol{\tau}^{B}\right)\right)\right),
$$

\footnotetext{
${ }^{17}$ Formally, the equilibrium requires restrictions on $\bar{\sigma}_{j \neq Z}$. See Persson and Tabellini (1999) for a derivation of these restrictions in a public goods framework.
} 
where $\phi_{Z}=\sum_{j \neq Z} \alpha_{j} \phi_{j}$ is the average density across the types of factor owners of district $Z{ }^{18}$ Compared to (3.5), this expression clearly depends only on what takes place in the marginal district.

Taking the derivative of (3.10) with respect to $t^{A}$, solving for the equilibrium $t$ under majoritarian elections gives:

$$
t^{M A J}=-\frac{y\left(t^{M A J}\right)\left(\phi_{M} \alpha_{M}\left(1+\alpha_{X}\right)-\phi_{X} \alpha_{X}\left(1+\alpha_{M}\right)\right)}{m^{\prime}\left(t^{M A J}\right)\left(1+\alpha_{M}\right)\left(\phi_{M} \alpha_{M}+\phi_{X} \alpha_{X}\right)},
$$

where $m^{\prime}\left(t^{M A J}\right)<0$. Solving for the optimal $e$ to obtain:

$$
e^{M A J}=\frac{y^{*}\left(e^{M A J}\right)\left(\phi_{X} \alpha_{X}\left(1+\alpha_{M}\right)-\phi_{M} \alpha_{M}\left(1+\alpha_{X}\right)\right)}{y^{* \prime}\left(e^{M A J}\right)\left(1+\alpha_{X}\right)\left(\phi_{M} \alpha_{M}+\phi_{X} \alpha_{X}\right)},
$$

where $y^{* \prime}\left(e^{M A J}\right)>0$.

Thus the government imposes a tax on foreign and domestic exports $\left(t^{M A J} \geq 0\right.$ and $\left.e^{M A J} \leq 0\right)$ given that $\phi_{M}>\phi_{X} \gamma$, where $\gamma \equiv \frac{\alpha_{X}\left(1+\alpha_{M}\right)}{\alpha_{M}\left(1+\alpha_{X}\right)} \cdot{ }^{19}$ The tax on imports raises the price of the import-competing good, while a tax on exports decreases the domestic price of the exporting good. This increases the reward to the specific factor used in the import-competing sector, and decreases the return to the specific input used by the exporting sector, whereas the welfare cost of a higher trade taxation is shared by all voters. This policy combination therefore inflicts a negative externality on those who own claims to the specific input used in the exporting sector, which is not

\footnotetext{
${ }^{18}$ This implies that group $Z$, which on average is ideologically neutral, does not necessarily have the highest number of ideologically neutral voters. However, the ideological bias, given by the relation $\bar{\sigma}_{X}<\bar{\sigma}_{Z}<\bar{\sigma}_{M}$, is assumed to be such that all electoral competition still concentrates on the marginal district.

${ }^{19}$ This condition is principally the same as the one determining trade policy under proportional institutions. Note that $\gamma=1$ when $\alpha_{X}=\alpha_{M}$, and $\gamma>1$ if $\alpha_{X}>\alpha_{M}$, but $\gamma<1$ whenever $\alpha_{X}<\alpha_{M}$. This reflects the fact that a higher (lower) taxation, under a majoritarian electoral rule, requires more swing voters among those with a common interest in the import-competing (exporting) sector in proportion to the share of individuals who own the input employed by the exporting (import-competing) industry. The reason is that, under a majoritarian system, the political power of the constituents in district $Z$, with stakes in sector $j \neq Z$, is relatively more dependent on the number of voters who own the factor used by the industry in question (that is, the parameter $\alpha_{j \neq Z}$ ). This can be seen from the specific structure of the candidates' goal functions, i.e., from (3.5) and (3.10).
} 
internalized by the voters with a common interest in the import-competing industry.

If $\phi_{M}<\phi_{X} \gamma$, the government subsidizes foreign and domestic exports $\left(t^{M A J} \leq 0\right.$ and $\left.e^{M A J} \geq 0\right)$. This decreases the price of imports and increases the domestic price of exports, which decreases the return to the specific factor used in the production of the import-competing good, and increases the reward to the specific input used in producing exports. The benefit of the lower price of imports, net of the subsidy cost, is shared by both types of factor owners. This creates a negative externality on the voters with a stake in the import-competing sector, who benefit as consumers but loses in terms of welfare as factor owners.

Whenever $\phi_{M}=\phi_{X} \gamma$ free trade prevails, and $t^{M A J}=e^{M A J}=0$.

The politically optimal trade-off between taxation and subsidies for electoral rule $k=P R O, M A J$ can be obtained by dividing $t^{k}$ with $e^{k}$ :

$$
\frac{t^{k}}{e^{k}}=\frac{y\left(t^{k}\right) y^{* \prime}\left(e^{k}\right)\left(1+\alpha_{X}\right)}{y^{*}\left(e^{k}\right) m^{\prime}\left(t^{k}\right)\left(1+\alpha_{M}\right)} .
$$

(3.13) is non-positive since either $t^{k} \geq 0$ and $e^{k} \leq 0$ if $\phi_{M}>\phi_{X}$ (or $\left.\phi_{M}>\phi_{X} \gamma\right)$, or $t^{k} \leq 0$ and $e^{k} \geq 0$ if $\phi_{M}<\phi_{X}$ (or $\phi_{M}<\phi_{X} \gamma$ ). Given that $\phi_{M}>\phi_{X}$ (or $\left.\phi_{M}>\phi_{X} \gamma\right)$, when the output of the import-competing good, $y\left(t^{k}\right)$, is higher and the volume of domestic exports, $y^{*}\left(e^{k}\right)$, is lower, voters with a stake in the import-competing sector have relatively more to gain from a higher import tariff than a higher export taxation. Intuitively, a higher import tariff solely benefits these voters in their capacity as factor owners, while the revenues from taxing exports are redistributed uniformly to all voters. Moreover, a higher value of the derivative of the export supply function, $y^{* \prime}\left(e^{k}\right)$, and a lower absolute value of the derivative of the import demand function, $m^{\prime}\left(t^{k}\right)$, imply that the deadweight loss from taxation of exports is high, whereas the social cost of import tariffs is low. This increases the benefit of taxing domestic exports at a relatively lower rate, and imports at a relatively higher rate.

If $\phi_{M}<\phi_{X}$ (or $\phi_{M}<\phi_{X} \gamma$ ), when the output of the domestic exporting good, $y^{*}\left(e^{k}\right)$, is higher, and the volume of the import-competing good, $y\left(t^{k}\right)$, is lower, voters with a stake in the exporting sector prefer a relatively higher rate of subsidies on domestic exports than on imports. The reason is that export subsidies increase the reward to the specific factor used in the exporting industry, while the benefit of a lower price on imports is shared by 
all voters. A higher absolute value of the derivative of the import demand function, $m^{\prime}\left(t^{k}\right)$, and a lower value of the derivative of the export supply function, $y^{* \prime}\left(e^{k}\right)$, implies that the social value of import subsidies is low, while the benefit of export subsidies is high due to a low elasticity of domestic export supply. This increases the welfare of subsidizing domestic exports at a relatively higher rate and imports at a relatively lower rate.

\subsection{Comparative Trade Policy}

Assuming that $m^{\prime}\left(t^{P R O}\right)=m^{\prime}\left(t^{M A J}\right)=m^{\prime}(t),{ }^{20}$ subtracting (3.11) from (3.8) produces: ${ }^{21}$

$$
t^{P R O}-t^{M A J}=-\frac{1}{m^{\prime}(t)}\left(y\left(t^{P R O}\right) \lambda^{P R O}-y\left(t^{M A J}\right) \lambda^{M A J}\right) .
$$

It can be established that (see Appendix A.1 for details) $t^{P R O}>t^{M A J}$ $\left(t^{P R O}<t^{M A J}\right)$ if there are relatively more factor owners in district $Z$ with stakes in the exporting (import-competing) sector. When $\alpha_{X}>\alpha_{M}\left(\alpha_{X}<\alpha_{M}\right)$ it is optimal for both candidates in a convergent electoral equilibrium to propose a relatively lower (higher) level of protection under majoritarian elections. Such a trade policy has the same political benefit to the parties as under a proportional system, namely the marginal votes gained among owners of the input used in the exporting (import-competing) sector, but the costs are smaller, as the parties do not internalize the votes lost in the nonmarginal district $M(X)$. The electoral competition is stiffer, because the candidates are relatively more focused on the type of factor owners who represents the largest fraction of the voting population in the district with the least average ideological bias. Since the election outcome is more sensitive to policy, the dominant, and therefore decisive, type in district $Z, \alpha_{X}\left(\alpha_{M}\right)$, obtains a trade policy closer to its bliss point as compared to proportional representation. This translates into a relatively less (more) protectionist stance.

\footnotetext{
${ }^{20}$ It can be shown that this assumption is valid in the case of linear import functions with the same slope under both electoral rules, as well as for concave functions with different slope coefficients.$$
{ }^{21} \lambda^{P R O} \equiv \frac{\left(1+\alpha_{X}\right)\left(\phi_{M}-\phi_{X}\right)}{\phi_{M}\left(1+\alpha_{M}\right)+\phi_{X}\left(1+\alpha_{X}\right)} \text { and } \lambda^{M A J} \equiv \frac{\phi_{M} \alpha_{M}\left(1+\alpha_{X}\right)-\phi_{X} \alpha_{X}\left(1+\alpha_{M}\right)}{\left(1+\alpha_{M}\right)\left(\phi_{M} \alpha_{M}+\phi_{X} \alpha_{X}\right)} \text {. }
$$ 
Let $y^{* \prime}\left(e^{P R O}\right)=y^{* \prime}\left(e^{M A J}\right)=y^{* \prime}(e),{ }^{22}$ subtracting (3.12) from (3.9) to obtain: ${ }^{23}$

$$
e^{P R O}-e^{M A J}=\frac{1}{y^{* \prime}(e)}\left(y^{*}\left(e^{P R O}\right) \delta^{P R O}-y^{*}\left(e^{M A J}\right) \delta^{M A J}\right) .
$$

It is shown in Appendix A.2 that $e^{P R O}>e^{M A J}\left(e^{P R O}<e^{M A J}\right)$ if there are relatively more factor owners in district $Z$ with stakes in the importcompeting (exporting) sector. If $\alpha_{M}>\alpha_{X}\left(\alpha_{M}<\alpha_{X}\right)$, the parties gain by announcing a less (more) supportive policy towards the export industry under majoritarian elections. As already noted, the majoritarian regime promotes a more intense political competition, which implies a trade policy that to a larger extent internalizes the benefits and costs of the voters that belong to the dominant fraction $\alpha_{M}\left(\alpha_{X}\right)$ of district $Z$. District $Z$ is an asymmetric replica of the entire population $\forall \alpha_{M} \neq \alpha_{X}$, where the factor owners with a stake in the import-competing (exporting) sector receive more weight. This asymmetry has the same effect as increasing the number of swing voters within the group of owners of the specific factor used by sector $M(X)$ under proportional elections, the result of which follows from (3.9)-less (more) export subsidies or a higher (lower) export taxation.

These results confirm the findings of Roelfsema (2004), Persson (2005), Grossman and Helpman (2005), and Willman (2008), as well as those of Hatfield and Hauk (2004), because the equilibrium level of protection can be comparatively lower, and higher, under the majoritarian electoral rule. The policy outcome depends on the relative size of the fraction of constituents in the marginal district with stakes in the exporting sector. Thus the framework presented here encompasses as special cases the earlier models reported in the literature.

Noting that $\lambda^{P R O}-\lambda^{M A J}=\frac{3\left(\alpha_{X}-\alpha_{M}\right) \phi_{M} \phi_{X}}{\left(1+\alpha_{M}\right)\left(\alpha_{M} \phi_{M}+\alpha_{X} \phi_{X}\right)\left(\phi_{M}\left(1+\alpha_{M}\right)+\phi_{X}\left(1+\alpha_{X}\right)\right)}$, differentiating this expression with respect to $\phi_{M}$ and $\phi_{X}$, evaluating at $\phi_{M}=$ $\phi_{X}$ gives:

\footnotetext{
${ }^{22}$ It can be shown that this assumption is valid in the case of linear export functions with the same slope under both electoral rules, as well as for convex functions with different slope coefficients.

${ }^{23} \delta^{P R O} \equiv \frac{\left(1+\alpha_{M}\right)\left(\phi_{X}-\phi_{M}\right)}{\phi_{M}\left(1+\alpha_{M}\right)+\phi_{X}\left(1+\alpha_{X}\right)}$ and $\delta^{M A J} \equiv \frac{\phi_{X} \alpha_{X}\left(1+\alpha_{M}\right)-\phi_{M} \alpha_{M}\left(1+\alpha_{X}\right)}{\left(1+\alpha_{M}\right)\left(\phi_{M} \alpha_{M}+\phi_{X} \alpha_{X}\right)}$.
} 


$$
\left.\frac{\partial\left(\lambda^{P R O}-\lambda^{M A J}\right)}{\phi_{M}}\right|_{\phi_{M}=\phi_{X}}=\frac{\left(\alpha_{M}-\alpha_{X}\right)\left(\alpha_{M}\left(1+\alpha_{M}\right)-\alpha_{X}\left(1+\alpha_{X}\right)\right)}{3 \phi_{j \neq Z}\left(1+\alpha_{M}\right)} \geq 0,
$$

and

$$
\left.\frac{\partial\left(\lambda^{P R O}-\lambda^{M A J}\right)}{\phi_{X}}\right|_{\phi_{M}=\phi_{X}}=-\frac{\left(\alpha_{M}-\alpha_{X}\right)\left(\alpha_{M}\left(1+\alpha_{M}\right)-\alpha_{X}\left(1+\alpha_{X}\right)\right)}{3 \phi_{j \neq Z}\left(1+\alpha_{M}\right)} \leq 0
$$

It is shown in Appendix A.3 that this implies:

$$
\left.\frac{\partial\left(t^{P R O}-t^{M A J}\right)}{\phi_{M}}\right|_{\phi_{M}=\phi_{X}} \geq 0
$$

and

$$
\left.\frac{\partial\left(t^{P R O}-t^{M A J}\right)}{\phi_{X}}\right|_{\phi_{M}=\phi_{X}} \leq 0
$$

The reason for these results can be explained as follows. By (3.5) and (3.10), the parties internalize the ideological homogeneity, $\phi_{j \neq Z}$, among the factor owners to a relatively larger extent under proportional elections compared with the majoritarian rule (by a factor of $1+\alpha_{j \neq Z}$ compared to $\alpha_{j \neq Z}$ ). Under the majoritarian system, on the other hand, the political influence is relatively more dependent on the number of voters with stakes in sector $j \neq Z$. Therefore, at free trade, where $\phi_{M}=\phi_{X}$, when the number of swing voters increases among those with a stake in the import-competing (exporting) sector, the level of protection under the proportional electoral rule increases (decreases) relatively more.

Differentiating $\delta^{P R O}-\delta^{M A J}=\frac{3\left(\alpha_{M}-\alpha_{X}\right) \phi_{M} \phi_{X}}{\left(1+\alpha_{X}\right)\left(\alpha_{M} \phi_{M}+\alpha_{X} \phi_{X}\right)\left(\phi_{M}\left(1+\alpha_{M}\right)+\phi_{X}\left(1+\alpha_{X}\right)\right)}$ with respect to $\phi_{M}$ and $\phi_{X}$, evaluating at $\phi_{M}=\phi_{X}$ to obtain:

$$
\left.\frac{\partial\left(\delta^{P R O}-\delta^{M A J}\right)}{\phi_{M}}\right|_{\phi_{M}=\phi_{X}}=-\frac{\left(\alpha_{M}-\alpha_{X}\right)\left(\alpha_{M}\left(1+\alpha_{M}\right)-\alpha_{X}\left(1+\alpha_{X}\right)\right)}{3 \phi_{j \neq Z}\left(1+\alpha_{X}\right)} \leq 0,
$$

and 


$$
\left.\frac{\partial\left(\delta^{P R O}-\delta^{M A J}\right)}{\phi_{X}}\right|_{\phi_{M}=\phi_{X}}=\frac{\left(\alpha_{M}-\alpha_{X}\right)\left(\alpha_{M}\left(1+\alpha_{M}\right)-\alpha_{X}\left(1+\alpha_{X}\right)\right)}{3 \phi_{j \neq Z}\left(1+\alpha_{X}\right)} \geq 0 .
$$

As shown in Appendix A.4, it follows that:

$$
\left.\frac{\partial\left(e^{P R O}-e^{M A J}\right)}{\phi_{M}}\right|_{\phi_{M}=\phi_{X}} \leq 0
$$

and

$$
\left.\frac{\partial\left(e^{P R O}-e^{M A J}\right)}{\phi_{X}}\right|_{\phi_{M}=\phi_{X}} \geq 0
$$

Using the same line of reasoning as above, the political parties take into account the level of ideological homogeneity relatively more under proportional elections. Hence, at free trade, as the number of swing voters increases among the agents with a stake in the import-competing (exporting) sector, the level of export support distributed under the proportional electoral rule decreases (increases) relative to the majoritarian case.

Up until now, there has been no conflict of interest between voters and their political representatives. In the following it is assumed that politicians are rent seeking. How do the candidates exploit their political power to appropriate resources for themselves at the voters' expense in a small open economy and under different electoral rules? Can the voters discipline politicians through the implicit incentives elections offer? Persson and Tabellini (1999) argue that since the electoral competition is stiffer under the majoritarian electoral rule, the parties become relatively more disciplined and forego some prospective political rents. Does their result hold in the current setting? These questions are addressed below.

\subsection{Electoral Competition and Equilibrium Rents}

To give an incentive for political rent seeking, suppose that the candidate winning the election captures a share $\gamma \in(0,1)$ of the tariff revenues; that is, $R=\gamma t m(t)$, where $t \geq 0$ and $R$ reflects endogenous rents to politicians - outright diversion of resources, such as corruption or party financing. Consider trade balance equilibrium, where the value of imports equals the value of exports: $\boldsymbol{\tau}_{H} m(t)=\boldsymbol{\tau}_{F} y^{*}(e)$, where $\boldsymbol{\tau}_{H}=\left(t_{H}, e_{F}\right)$ denotes the vector 
of domestic trade policies affecting aggregate imports to the small open economy (i.e., the domestic tariff, $t_{H}$, and the foreign export subsidy or export tax, $e_{F}$, levied on domestic imports), and $\boldsymbol{\tau}_{F}=\left(t_{F}, e_{H}\right)$ is the corresponding vector of foreign policy instruments levied on domestic exports. Further, assume symmetric trade policies, that is, $\boldsymbol{\tau}_{H}=\boldsymbol{\tau}_{F}$, such that $m(t)=y^{*}(e)$, which gives $t=\frac{R}{\gamma y^{*}(e)}$.

The timing of the political process is the same as in Subsection 3.1. (1) The two candidates, simultaneously and noncooperatively, announce their policy: $\boldsymbol{q}^{A}=\left(R^{A}, e^{A}\right)$ and $\boldsymbol{q}^{B}=\left(R^{B}, e^{B}\right)$. Since $\gamma$ is a parameter and $t=\frac{R}{\gamma y^{*}(e)}$, this yields the domestic policy vector $\boldsymbol{\tau}=(t, e)$. At this stage, the parties know the voters' policy preferences. They also know the distributions of the ideology and popularity parameters, $\sigma_{i j}$ and $\delta$, but not yet their realized values. (2) The actual value of $\delta$ is realized and all uncertainty is resolved. (3) Elections are held. (4) The elected candidate implements the announced policy platform.

When announcing policy, party $A$ maximizes the expected value of rents:

$$
E\left(v^{A}\right)=P_{A} R^{A} .
$$

Suppose for simplicity that in equilibrium, the trade tax revenues that accrues to the voters are matched by the subsidies distributed to the domestic exporters: $(1-\gamma) t^{A} m\left(t^{A}\right)=e^{A} y^{*}\left(e^{A}\right)$. This means that $r\left(\boldsymbol{\tau}^{A}\right)=0$, since $r\left(\boldsymbol{\tau}^{A}\right) \equiv \frac{(1-\gamma) t^{A} m\left(t^{A}\right)-e^{A} y^{*}\left(e^{A}\right)}{3} \cdot{ }^{24}$ The welfare associated with candidate $A$ of a representative owner of the specific factor used in industry $M$ and $X$ can thus be reproduced as:

$$
W_{M}\left(R^{A}\right)=l+\bar{\pi}\left(\frac{R^{A}}{\gamma y^{*}(e)}\right)+s\left(\frac{R^{A}}{\gamma y^{*}(e)}\right),
$$

and

$$
W_{X}\left(R^{A}\right)=l+\bar{\pi}^{*}\left(e^{A}\right)+s\left(\frac{R^{A}}{\gamma y^{*}(e)}\right),
$$

\footnotetext{
${ }^{24}$ This assumption affects the equilibrium level of rents under the different electoral rules, but not the relative level, since $r\left(\boldsymbol{\tau}^{A}\right)$ enters symmetrically into the candidates' objective functions under both majoritarian and proportional elections. The focus of this paper is on the relative level.
} 
where $W_{M}\left(R^{B}\right)$ and $W_{X}\left(R^{B}\right)$ are defined analogously. Since both candidates share the same first-order conditions, a unique equilibrium exists in which both $A$ and $B$ choose the same $R$.

Taking the first-order condition of (3.24) for $R^{A}$ to obtain:

$$
\frac{\partial P_{A}}{\partial R^{A}} R^{A}+P_{A}=\frac{\partial P_{A}}{\partial R^{A}} R^{A}+\frac{1}{2}=0,
$$

where the second equality exploits that $P_{A}=\frac{1}{2}$, since $R^{A}=R^{B}$ in equilibrium. Using (3.25) and (3.26) in the derivative of (3.5) with respect to $R^{A}$, substituting the resulting expression in (3.27), to obtain the equilibrium rents under proportional representation:

$$
R^{P R O}=\max \left(0, \tilde{R}^{P R O}\right)
$$

where:

$$
\tilde{R}^{P R O}=\frac{9 \phi \gamma y^{*}\left(e^{P R O}\right)}{2 \psi\left(\left(y^{*}\left(e^{P R O}\right)+y\left(\tilde{R}^{P R O}\right)\right) \phi-y^{*}\left(e^{P R O}\right) y\left(\tilde{R}^{P R O}\right) \phi_{M} \gamma\right)},
$$

where $\phi \equiv \frac{\sum_{j} \phi_{j}}{3}$.

(3.29) is decreasing in $\psi$, the density of the distribution of the popularity parameter $\delta$. The uncertain outcome of the relative political popularity means that the identity of the swing voters is not known. This creates electoral uncertainty, which weakens the electoral competition, as a candidate's probability of winning falls only at the finite rate $\psi$ for a marginal increase in rents. The lower is this rate, that is, the more uncertain is the election outcome, the larger is the scope for seeking rents. Also, by differentiating (3.29) it can be shown that $\tilde{R}^{P R O}$ is increasing in $\phi_{M}$ and decreasing in $\phi_{X}$. Intuitively, higher rents imply higher tariffs, since $t=\frac{R}{\gamma y^{*}(e)}$. This solely benefits the voters with stakes in the import-competing industry by raising the return to the specific factor used in this sector, while the welfare cost of higher rents is borne by both types of factor owners. Hence, when the number of swing voters increases within the group of owners of the specific factor used by industry $M(X)$, the optimal rents increase (decrease).

Using (3.25) and (3.26) in the derivative of (3.10) with respect to $R^{A}$, substituting the resulting expression in (3.27), solving for the equilibrium rents under the majoritarian electoral rule to obtain: 


$$
R^{M A J}=\max \left(0, \tilde{R}^{M A J}\right)
$$

where:

$$
\tilde{R}^{M A J}=\frac{9 \phi_{Z} \gamma y^{*}\left(e^{M A J}\right)\left(1+\alpha_{M}\right)}{2 \psi\left(\left(y^{*}\left(e^{M A J}\right)+y\left(\tilde{R}^{M A J}\right)\right) \phi_{Z}\left(1+\alpha_{M}\right)-3 y^{*}\left(e^{M A J}\right) y\left(\tilde{R}^{M A J}\right) \alpha_{M} \phi_{M} \gamma\right)},
$$

where $\phi_{Z}=\sum_{j \neq Z} \alpha_{j} \phi_{j} . \tilde{R}^{M A J}$ is decreasing in $\psi$, and it is straightforward to verify that (3.31) is increasing in $\phi_{M}$ and decreasing in $\phi_{X}$. The intuition is the same as under proportional elections.

Assuming that $y\left(\tilde{R}^{P R O}\right)=y\left(\tilde{R}^{M A J}\right)=y(\tilde{R})$ and $y^{*}\left(e^{P R O}\right)=y^{*}\left(e^{M A J}\right)=$ $y^{*}(e),{ }^{25}$ subtracting (3.31) from (3.29) gives:

$$
\tilde{R}^{P R O}-\tilde{R}^{M A J}=\frac{\left(\alpha_{X}-\alpha_{M}\right) \phi_{M} \phi_{X} \gamma^{2} y^{* 2}(e) y(\tilde{R})}{\psi \Omega},
$$

where $\Omega>0$ if $\tilde{R}^{P R O} \geq 0$ and $\tilde{R}^{M A J} \geq 0$ or $\tilde{R}^{P R O} \leq 0$ and $\tilde{R}^{M A J} \leq 0 .{ }^{26}$ $\tilde{R}^{P R O}>\tilde{R}^{M A J}\left(\tilde{R}^{P R O}<\tilde{R}^{M A J}\right)$ if there are relatively more factor owners in district $Z$ with stakes in the exporting (import-competing) industry. When $\alpha_{X}>\alpha_{M}\left(\alpha_{X}<\alpha_{M}\right)$, the parties gain by announcing relatively lower (higher) rents under majoritarian representation. Lower (higher) rents translate into a less (more) protectionist trade policy, which is preferred by the voter group that owns the factor used in the exporting (import-competing) sector. The stiffer majoritarian electoral competition makes it politically optimal to propose a policy closer to the bliss point of the decisive fraction of the voters in the marginal district, $\alpha_{X}\left(\alpha_{M}\right)$; that is, less (more) political rents. Hence, in contrast to the result of Persson and Tabellini (1999), more rents do not necessarily make the candidates lose votes at a higher rate under majoritarian elections. As shown here, the relative level of rent seeking depends on the relative number of voters in the swing districts who own the factor specific to the exporting industry.

\footnotetext{
${ }^{25}$ It can be shown that $y\left(\tilde{R}^{P R O}\right)=y\left(\tilde{R}^{M A J}\right)$ is satisfied for linear and convex importcompeting supply functions with different slope coefficients, while $y^{*}\left(e^{P R O}\right)=y^{*}\left(e^{M A J}\right)$ is satisfied for linear and convex export supply functions with different slope coefficients.

${ }^{26} \Omega=\frac{2\left(\left(y^{*}\left(e^{P R O}\right)+y\left(\tilde{R}^{P R O}\right)\right) \phi-y^{*}\left(e^{P R O}\right) y\left(\tilde{R}^{P R O}\right) \phi_{M} \gamma\right)\left(\left(y^{*}\left(e^{M A J}\right)+y\left(\tilde{R}^{M A J}\right)\right) \phi_{Z}\left(1+\alpha_{M}\right)-3 y^{*}\left(e^{M A J}\right) y\left(\tilde{R}^{M A J}\right) \alpha_{M} \phi_{M} \gamma\right)}{27}$. That is, $\Omega>0$ if the denominator of (3.29) and (3.31) is simultaneously non-negative or non-positive, i.e., if $\tilde{R}^{P R O} \geq 0$ and $\tilde{R}^{M A J} \geq 0$ or $\tilde{R}^{P R O} \leq 0$ and $\tilde{R}^{M A J} \leq 0$.
} 


\section{Conclusions}

Recent research has found somewhat ambiguous evidence about the relationship between the relative level of trade protection in a country and the type of electoral rule employed. This paper suggests a possible solution to the indeterminacy by explicitly incorporating an export industry, producing for foreign markets using a sector-specific factor, into a model of endogenous trade policy with probabilistic voting. On the basis of this framework, it is shown that trade policy is more (less) restrictive under proportional electoral regimes, as compared to majoritarian institutions, if swing districts are populated by relatively more (less) factor owners with stakes in the exporting sector. The reason is that the election outcome under a majoritarian system is more sensitive to policy. Therefore, the dominant, or decisive, type of input owners in the marginal districts obtains a trade policy closer to its optimum, in relation to proportional representation, which translates into a relatively less (more) protectionist policy stance in equilibrium.

The paper also provides some insights into rent seeking in a small open economy from a comparative political economy perspective. Persson and Tabellini (1999) show that because of the more intense political competition under the majoritarian regime, parties become more disciplined and forego some prospective rents. This is, however, not consistent with the observation that countries that apply the majoritarian system rate as less democratic, where rent seeking is high. The argument provided in this paper is that politicians optimally apply a lower (higher) level of rent seeking under the majoritarian electoral rule if and only if there are relatively more factor owners in the swing districts with stakes in the exporting (import-competing) sector. 


\section{References}

Balistreri, E. (1997) "The Performance of the Heckscher-Ohlin-Vanek Model in Predicting Endogenous Policy Forces at the Individual Level", Canadian Journal of Economics, vol. 30, pp. 1-17.

Beaulieu, E. (2002) "Factor or Industry Cleavages in Trade Policy? An Empirical Analysis of the Stolper-Samuelson Theorem", Economics and Politics, vol. 14, pp. 99-131.

Berry, W. D., Fording, R. C., Hanson, R. L. and Ringquist E. V. (1998) "Measuring Citizen and Government Ideology in the American States, 1960-93", American Journal of Political Science, vol. 42, pp. 327-348.

Busch, M. L. and Reinhardt, E. (1999) "Industrial Location and Protection: The Political and Economy Geography of U.S. Nontariff Barriers", American Journal of Political Science, vol. 43, pp. 1028-1050.

Dorussen, H., Enelow, J. M. and Lin, T. (1999) "Equilibrium in Multicandidate Probabilistic Spatial Voting", Public Choice, vol. 98, pp. 59-82.

Chang, R., Fung, K. C. and Lin, C. C. (2009) "Political Economy of Strategic Trade Policies", Review of International Economics, vol. 17, pp. 494-509.

Grossman, G. and Helpman, E. (1994) "Protection for Sale", American Economic Review, vol. 84, pp. 833-850.

Grossman, G. and Helpman, E. (2005) "A Protectionist Bias in Majoritarian Politics", Quarterly Journal of Economics, vol. 120, pp. 1239-1282.

Hatfield, J. W. and Hauk, W. R. (2004) "The Effects of the Electoral Regime on Trade Policy" (Stanford Institute for Economic Policy Research: Mimeo).

Lindbeck, A. and Weibull, J. (1987) "Balanced-Budget Redistribution as the Outcome of Political Competition", Public Choice, vol. 52, pp. 273-297.

Norris, P. (2008) Driving Democracy: Do Power-Sharing Institutions Work? (New York: Cambridge University Press). 
Persson, T. (2005) "Forms of Democracy, Policy and Economic Development", NBER Working Paper 11171.

Persson, T. and Tabellini, G. (1999) "The Size and Scope of Government: Comparative Politics with Rational Politicians", European Economic Review, vol. 43, pp. 699-735.

Persson, T. and Tabellini, G. (2002) Political Economics: Explaining Economic Policy (Cambridge, Massachusetts: MIT Press).

Pettersson-Lidbom P. (2008) "Do Parties Matter for Economic Outcomes: A Regression-Discontinuity Approach", Journal of the European Economic Association, vol. 6, pp. 1037-1056.

Roelfsema, H. (2004) "Political Institutions and Trade Protection" (Utrecht School of Economics: Mimeo).

Scheve, K. and Slaughter, M. (2001) "What Determines Individual Trade Policy Preferences?", Journal of International Economics, vol. 54, pp. 267-292.

United States Department of Agriculture (2004) http://www.fas.usda.gov/ scriptsw/wtopdf/wtopdf_frm.asp.

Willmann, G. (2008) "Why Legislators are Protectionists: The Role of Majoritarian Voting in Setting Tariffs", Journal of International Economics (forthcoming). 


\section{A Appendix}

\section{A.1 Determining the Sign of (3.14)}

Consider the case where $t^{P R O}>0$ and $t^{M A J}>0$, such that $\lambda^{P R O}>0$ and $\lambda^{M A J}>0$. It follows from (3.14) that $t^{P R O}>t^{M A J}$ if $\frac{\lambda^{P R O}}{\lambda^{M A J}}>\frac{y\left(t^{M A J}\right)}{y\left(t^{P R O}\right)}$. The inequality $t^{P R O}>t^{M A J}$ implies that $\frac{y\left(t^{M A J}\right)}{y\left(t^{P R O}\right)}<1$, since the supply curve of the import-competing commodity is upward-sloping. $\lambda^{P R O}-\lambda^{M A J}=$ $\frac{3\left(\alpha_{X}-\alpha_{M}\right) \phi_{M} \phi_{X}}{\left(1+\alpha_{M}\right)\left(\alpha_{M} \phi_{M}+\alpha_{X} \phi_{X}\right)\left(\phi_{M}\left(1+\alpha_{M}\right)+\phi_{X}\left(1+\alpha_{X}\right)\right)}$. Hence, $\frac{\lambda^{P R O}}{\lambda^{M A J}}>1>\frac{y\left(t^{M A J}\right)}{y\left(t^{P R O}\right)}$ if and only if $\alpha_{X}>\alpha_{M}$. Thus, $t^{P R O}>t^{M A J}$ if and only if $\alpha_{X}>\alpha_{M}$. By the same argument, $t^{P R O}<t^{M A J}$ if and only if $\alpha_{X}<\alpha_{M}$.

If, on the other hand, $t^{P R O}<0$ and $t^{M A J}<0$, such that $\lambda^{P R O}<0$ and $\lambda^{M A J}<0$, then $t^{P R O}>t^{M A J}$ if $\frac{\lambda^{P R O}}{\lambda^{M A J}}<\frac{y\left(t^{M A J}\right)}{y\left(t^{P R O}\right)}$. Likewise, $\frac{y\left(t^{M A J}\right)}{y\left(t^{P R O}\right)}<1$ when $t^{P R O}>t^{M A J}$. In this case, a necessary, but not sufficient, condition for $t^{P R O}>t^{M A J}$ to be satisfied is given by: $\lambda^{P R O}-\lambda^{M A J}>0$, which is true if and only if $\alpha_{X}>\alpha_{M}$. Using the same line of reasoning, it follows that the necessary, but not sufficient, condition for $t^{P R O}<t^{M A J}$ to hold is that $\alpha_{X}<\alpha_{M}$.

Moreover, it should be noted that $t^{P R O}=t^{M A J}$ if $\alpha_{X}=\alpha_{M}$.

\section{A.2 Determining the Sign of (3.15)}

Assume that $e^{P R O}>0$ and $e^{M A J}>0$, such that $\delta^{P R O}>0$ and $\delta^{M A J}>0$. From (3.15) it is clear that $e^{P R O}>e^{M A J}$ if $\frac{\delta^{P R O}}{\delta^{M A J}}>\frac{y^{*}\left(e^{M A J}\right)}{y^{*}\left(e^{P R O}\right)} \cdot e^{P R O}>$ $e^{M A J}$ implies that $\frac{y^{*}\left(e^{M A J}\right)}{y^{*}\left(e^{P R O}\right)}<1$, since the supply curve of domestic exports is upward-sloping. $\delta^{P R O}-\delta^{M A J}=\frac{3\left(\alpha_{M}-\alpha_{X}\right) \phi_{M} \phi_{X}}{\left(1+\alpha_{X}\right)\left(\alpha_{M} \phi_{M}+\alpha_{X} \phi_{X}\right)\left(\phi_{M}\left(1+\alpha_{M}\right)+\phi_{X}\left(1+\alpha_{X}\right)\right)}$. Therefore, $\frac{\delta^{P R O}}{\delta^{M A J}}>1>\frac{y^{*}\left(e^{M A J}\right)}{y^{*}\left(e^{P R O}\right)}$ if and only if $\alpha_{M}>\alpha_{X}$. Consequently, $e^{P R O}>e^{M A J}$ if and only if $\alpha_{M}>\alpha_{X}$. Using the same argument, $e^{P R O}<$ $e^{M A J}$ if and only if $\alpha_{M}<\alpha_{X}$.

If $e^{P R O}<0$ and $e^{M A J}<0$, such that $\delta^{P R O}<0$ and $\delta^{M A J}<0$, then $e^{P R O}>e^{M A J}$ if $\frac{\delta^{P R O}}{\delta^{M A J}}<\frac{y^{*}\left(e^{M A J}\right)}{y^{*}\left(e^{P R O}\right)} \cdot \frac{y^{*}\left(e^{M A J}\right)}{y^{*}\left(e^{P R O}\right)}<1$ when $e^{P R O}>e^{M A J}$. Hence, a necessary, but not sufficient, condition for $e^{P R O}>e^{M A J}$ to be satisfied is given by: $\delta^{P R O}-\delta^{M A J}>0$. This holds if and only if $\alpha_{M}>\alpha_{X}$. It follows 
that the necessary, but not sufficient, condition for $e^{P R O}<e^{M A J}$ to hold is that $\alpha_{M}<\alpha_{X}$.

$$
e^{P R O}=e^{M A J} \text { if } \alpha_{M}=\alpha_{X} .
$$

\section{A.3 Determining the Sign of (3.18) and (3.19)}

$$
t^{P R O}=-\frac{y\left(t^{P R O}\right)\left(1+\alpha_{X}\right)\left(\phi_{M}-\phi_{X}\right)}{m^{\prime}\left(t^{P R O}\right)\left(\phi_{M}\left(1+\alpha_{M}\right)+\phi_{X}\left(1+\alpha_{X}\right)\right)}=-\frac{y\left(t^{P R O}\right)}{m^{\prime}\left(t^{P R O}\right)} \lambda^{P R O},
$$

where $\lambda^{P R O} \equiv \frac{\left(1+\alpha_{X}\right)\left(\phi_{M}-\phi_{X}\right)}{\phi_{M}\left(1+\alpha_{M}\right)+\phi_{X}\left(1+\alpha_{X}\right)}$.

$$
t^{M A J}=-\frac{y\left(t^{M A J}\right)\left(\phi_{M} \alpha_{M}\left(1+\alpha_{X}\right)-\phi_{X} \alpha_{X}\left(1+\alpha_{M}\right)\right)}{m^{\prime}\left(t^{M A J}\right)\left(1+\alpha_{M}\right)\left(\phi_{M} \alpha_{M}+\phi_{X} \alpha_{X}\right)}=-\frac{y\left(t^{M A J}\right)}{m^{\prime}\left(t^{M A J}\right)} \lambda^{M A J}
$$

where $\lambda^{M A J} \equiv \frac{\phi_{M} \alpha_{M}\left(1+\alpha_{X}\right)-\phi_{X} \alpha_{X}\left(1+\alpha_{M}\right)}{\left(1+\alpha_{M}\right)\left(\phi_{M} \alpha_{M}+\phi_{X} \alpha_{X}\right)}$.

Hence, if $\left.\frac{\partial\left(\lambda^{P R O}-\lambda^{M A J}\right)}{\phi_{M}}\right|_{\phi_{M}=\phi_{X}} \geq 0$ and $\left.\frac{\partial\left(\lambda^{P R O}-\lambda^{M A J}\right)}{\phi_{X}}\right|_{\phi_{M}=\phi_{X}} \leq 0$, then $\left.\frac{\partial\left(t^{P R O}-t^{M A J}\right)}{\phi_{M}}\right|_{\phi_{M}=\phi_{X}} \geq 0$ and $\left.\frac{\partial\left(t^{P R O}-t^{M A J}\right)}{\phi_{X}}\right|_{\phi_{M}=\phi_{X}} \leq 0$ must hold.

\section{A.4 Determining the Sign of (3.22) and (3.23)}

$$
e^{P R O}=\frac{y^{*}\left(e^{P R O}\right)\left(1+\alpha_{M}\right)\left(\phi_{X}-\phi_{M}\right)}{y^{* \prime}\left(e^{P R O}\right)\left(\phi_{M}\left(1+\alpha_{M}\right)+\phi_{X}\left(1+\alpha_{X}\right)\right)}=\frac{y^{*}\left(e^{P R O}\right)}{y^{* \prime}\left(e^{P R O}\right)} \delta^{P R O},
$$

where $\delta^{P R O} \equiv \frac{\left(1+\alpha_{M}\right)\left(\phi_{X}-\phi_{M}\right)}{\phi_{M}\left(1+\alpha_{M}\right)+\phi_{X}\left(1+\alpha_{X}\right)}$.

$$
e^{M A J}=\frac{y^{*}\left(e^{M A J}\right)\left(\phi_{X} \alpha_{X}\left(1+\alpha_{M}\right)-\phi_{M} \alpha_{M}\left(1+\alpha_{X}\right)\right)}{y^{* \prime}\left(e^{M A J}\right)\left(1+\alpha_{M}\right)\left(\phi_{M} \alpha_{M}+\phi_{X} \alpha_{X}\right)}=\frac{y^{*}\left(e^{M A J}\right)}{y^{* \prime}\left(e^{M A J}\right)} \delta^{M A J}
$$

where $\delta^{M A J} \equiv \frac{\phi_{X} \alpha_{X}\left(1+\alpha_{M}\right)-\phi_{M} \alpha_{M}\left(1+\alpha_{X}\right)}{\left(1+\alpha_{M}\right)\left(\phi_{M} \alpha_{M}+\phi_{X} \alpha_{X}\right)}$.

Thus, if $\left.\frac{\partial\left(\delta^{P R O}-\delta^{M A J}\right)}{\phi_{M}}\right|_{\phi_{M}=\phi_{X}} \leq 0$ and $\left.\frac{\partial\left(\delta^{P R O}-\delta^{M A J}\right)}{\phi_{X}}\right|_{\phi_{M}=\phi_{X}} \geq 0$, then $\left.\frac{\partial\left(e^{P R O}-e^{M A J}\right)}{\phi_{M}}\right|_{\phi_{M}=\phi_{X}} \leq 0$ and $\left.\frac{\partial\left(e^{P R O}-e^{M A J}\right)}{\phi_{X}}\right|_{\phi_{M}=\phi_{X}} \geq 0$ is satisfied. 